\title{
Suitability of contact temperature sensors for kinetic temperature reference measurements in thermography
}

\author{
by A. Moya-González*, J. García-Hierro**, B. Diezma*, J.I. Robla**, N. Oeggerli*, E.C. Correa*
}

* Universidad Politécnica de Madrid, Escuela Técnica Superior de Ingeniería Agronómica, Alimentaria y de Biosistemas, Departamento de Ingeniería Agroforestal, Av. Puerta de Hierro, $n^{\circ} 2$ - 4, 28040 Madrid, Spain, adolfo.moya@upm.es

** Consejo Superior de Investigaciones Científicas, Centro Nacional de Investigaciones Metalúrgicas (CENIM), Avda. Gregorio del Amo, 8, 28040 Madrid

\begin{abstract}
The present work introduces the relevance of having more precise emissivity measurements for agricultural materials suitable for present applications. The values reported at the bibliography were mostly determined for remote sensing applications decades ago. The wide variation ranges for some samples and the current availability of better sensors suggest that the procedures for emissivity determination could be analysed and improved by the use of faster and more accurate temperature sensors. For this purpose, several temperature sensors have been evaluated regarding their time response, stability, and suitability for monitoring kinetic temperatures of crop samples.
\end{abstract}

\section{Introduction}

The use of thermographic images has spread in recent decades. As stated at the QIRT's website: "While the beauty of thermographic images and the ease of getting them could explain the success of this technique, the difficulty of getting accurate measurements using "thermal cameras" has caused a certain disaffection toward it". It was the discussion and dissemination of the advances on IR Thermography what inspired the constitution of the QIRT organization itself, as well as the conference and working groups.

The application of IR Thermography in crops has interested researchers mainly focused in remote sensing using satellite images, and the studies conducted during the 20th century for the determination of emissivity of crops often result in a wide variation range that however was suitable for their applications. Rubio et al. [1] analysed two field methods for the emissivity determination of several vegetation samples and compared their results with others based on in situ measurements reporting variations on the emissivity values for grass from 0.949 to 0.990 .

The differences in the emissivity values found in the literature for several agricultural samples can lead to deviations in the estimated temperature with respect to the real one. These deviations will be or not assumable depending on the application.

Van Alstyne and Olson [2] reported a $1^{\circ} \mathrm{C}$ measurement error when the set emissivity was within -0.07 and 0.05 of the actual emissivity at $22^{\circ} \mathrm{C}$.

Besides, it must be taken account the environmental temperature and the value of emissivity. Minkina et al. [3], simulated the effect on the estimation of surface temperature of an object including different levels of error in the emissivity or the environmental temperature, they found that under some conditions the greatest effect on error of temperature estimation was the error associated with the emissivity. Other example proposed by the authors at [4] focussed on the experimental evaluation of the surface emissivity of a central heating radiator under stationary conditions of heat exchange compares the temperature measurements of several defined points measured either with contact temperature sensors and thermography. In this case they assumed a limiting error of the contact measurements equal to $\pm 0.5^{\circ} \mathrm{C}$ which resulted on a limiting error equal to \pm 0.02 for the emissivity estimation. This error will eventually affect the temperature measurement error by thermography proportionally to the difference between the reflected temperature and the temperature of the specimen, which, depending on the case, may be greater than that existing during the proposed determination 
Table 1 shows the estimated temperatures $\left(T_{s}^{*}\right)$ for grass considering different emissivity values $\left(\varepsilon_{\text {grass }}\right)$ in the range referred by Rubio et al. [1], for current temperature of the sample of $24.85^{\circ} \mathrm{C}$ (then assuming 0.990 as the actual emissivity value) and a reflected temperature $\left(T_{\text {ref }}\right)$ of $-10.15^{\circ} \mathrm{C}$. Temperature estimation error reaches $3.09^{\circ} \mathrm{C}$ for this case.

Table 1. Sample temperatures for different emissivity values for grass within the range referred to in the bibliography at [1].

\begin{tabular}{|c|c|c|}
\hline$T_{\text {ref }}(\mathrm{k}):$ & $\varepsilon_{\text {grass: }}$ & $\mathrm{T}_{\mathrm{s}}{ }^{*}(\mathrm{k}):$ \\
\hline 263.00 & 0.990 & 298.00 \\
\hline 263.00 & 0.980 & 298.76 \\
\hline 263.00 & 0.970 & 299.52 \\
\hline 263.00 & 0.960 & 300.30 \\
\hline 263.00 & 0.950 & 301.09 \\
\hline
\end{tabular}

In agricultural field, the use of remote sensing for monitoring soil- and crop- water status regarding irrigation purposes is being widely studied. Some methodologies for estimating crop water status and irrigation management make use of the surface temperature of vegetation estimated by infrared thermography [5]. It may be mentioned a simple method for scheduling irrigation based on a time temperature threshold (TTT) for canopy that is achieving positive results [6]. However, is important to notice that the rules for trigger irrigation are based on the accumulated time when the crop is above a specified temperature. For example, Lamm et al. [7] compared three irrigation treatments with TTT values of 2.5 $\mathrm{h}$, or $5.5 \mathrm{~h}$ or above a canopy temperature of $28^{\circ} \mathrm{C}$; O'Shaughness, Evett [8] triggered only after canopy temperatures exceeded $28{ }^{\circ} \mathrm{C}$ for more than 452 min accumulated in a $24 \mathrm{~h}$ period. Assuming variations in the emissivity of 0.05 , such as those that have been included in Table 1, the irrigation schedule would be seriously altered.

An evaluation of the emissivity values should be done, for this purpose the emissivity determination methods should be reviewed and improved in order to estimate accurate values suitable for present applications such as irrigation planning. The characterization of sensors in order to select the most suitable ones to estimate kinetic temperatures of samples and references during the emissivity estimation procedures is paramount. In this work several Resistance Temperature Detectors (RTDs) and Thermoelectric Sensors (TCS) have been evaluated regarding its time responses, accuracy and suitability for measuring effectively surface temperature of samples.

\section{Materials and Methods}

Three commercial models of Type T TCs and three models of RTDs have been tested (Fig. 1):

- Isolated with PFA TC and wires of $2 \times 0.02 \mathrm{~mm}$ of diameter (TC1),

- Isolated with PTFE TC and wires of $2 \times 0.02 \mathrm{~mm}$ of diameter (TC2),

- Isolated with PTFE TC and wires of $2 \times 0.035 \mathrm{~mm}$ of diameter (TC3)

- $\quad$ Flat film RTD of $2.0 \times 2.3 \mathrm{~mm}$ class A (RTD1)

- Flat film RTD of $2.0 \times 10 \mathrm{~mm}$ class A (RTD2)

- Encapsulated RTD of $5 \mathrm{~mm}$ of diameter class A (RTD3)

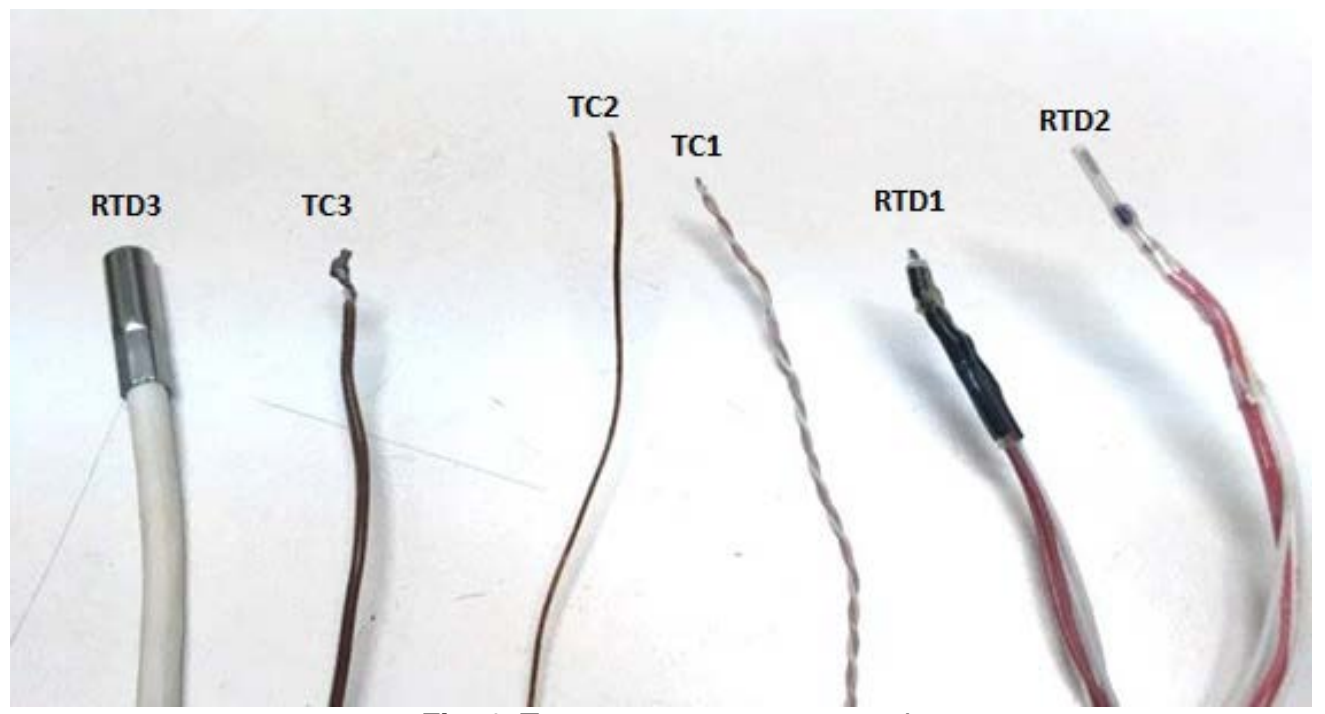

Fig. 1. Temperature sensors tested 
Several experiments were conducted in order to characterize some of the aforementioned contact temperature sensors (Table 2).

Table 2. Summary of experiments conducted for the contact temperature measurement sensors characterization

\begin{tabular}{|l|l|l|}
\hline Experiment & Objectives & Material \\
\hline Time response & $\begin{array}{l}\text { Determine the time response of } \\
\text { sensors }\end{array}$ & $\begin{array}{l}\text { Data acquisition modules / } 4 \\
\text { thermocouples / 4 pt100s / Bath of ice } \\
\text { and boiling water }\end{array}$ \\
\hline $\begin{array}{l}\text { Precision, noise } \\
\text { and accuracy }\end{array}$ & $\begin{array}{l}\text { Determination of precision noise } \\
\text { and accuracy of the sensors }\end{array}$ & $\begin{array}{l}\text { Data acquisition modules / } 4 \\
\text { thermocouples / 4 pt100s / Bath of ice } \\
\text { and boiling water }\end{array}$ \\
\hline Hysteresis & $\begin{array}{l}\text { Definition of the hysteresis of a } \\
\text { RTD sensor } \\
\text { Inhomogeneity }\end{array}$ & $\begin{array}{l}\text { Data acquisition modules / 1 pt100s / } \\
\text { Bath of ice and boiling water } \\
\text { inhomogeneity in thermocouples }\end{array}$ \\
\hline Calibration & $\begin{array}{l}\text { Data acquisition modules / } 4 \\
\text { thermocouples/ bath of water }\end{array}$ \\
\hline
\end{tabular}

Data were collected in a computer using ADAM series data acquisition modules (ADVANTECH Co., Ltd, Kunshan, China); for TC (ADAM-4019+ model), and RTD sensors (ADAM-4015 model) (Fig. 2). These models are intelligent sensor-to-computer interface element containing built-in microprocessors that can be remotely controlled through a simple set of commands which are issued in ASCII format. The maximum sampling rate is of 10 samples per second and the accuracy of the measurements is $\pm 0.1 \%$. Data were collected by the use of the program CEC TestPoint ${ }^{\circledR}$ and analyzed via Excel ${ }^{\circledR}$ and Matlab ${ }^{\circledR}$.

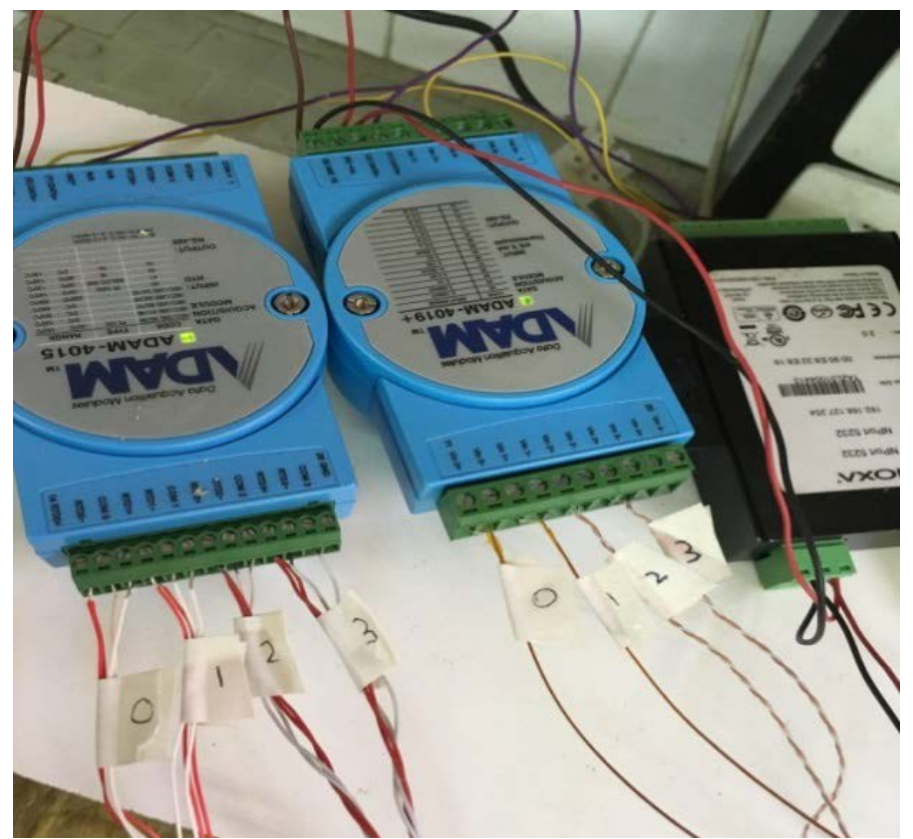

Fig. 2. RTD and TC sensors connected to ADAM modules

In order to characterize and calibrate the sensors, experiments were performed. Firstly, to determine the time response, all sensors were transferred instantaneously and simultaneously from a bath of ice to a bath of boiling distilled water and vice-versa, until reaching constant temperature in each case. Every output were recorded and plotted to determine the time response and the hysteresis of each single sensor. Once temperature measurements were stable recorded data were used for determination of precision and accuracy of the sensors.

To assure that the sensors provide a correct output, they had to be calibrated. The calibration was done against references of known actual temperature, as boiling water or a bath of ice (both using distillated water). The temperatures 
of the boiling water and bath of ice were determined based on atmospheric pressure, hourly registered at the 'Retiro' weather station in Madrid (4.7 km far and less than $10 \mathrm{~m}$ difference over sea level from the laboratory were measurements were conducted).

The calibration line for each sensor was then determined by knowing precisely the reference temperatures, $0^{\circ} \mathrm{C}$ for the bath of ice ("T $\mathrm{T}_{\text {Reflow") }}$ and $97.81^{\circ} \mathrm{C}$ for the boiling water ("T RefHigh") during the experiment (atmospheric pressure equal to $936.3 \mathrm{hPa}$ ). Calibration involves the alignment of the accurate measurement with what the system actually measures. A two point calibration was implemented to rescale the output and to correct both slope and offset error. In that case, two point calibration can be used because the sensor output is reasonably lineal over the measurement range, one in the high end of measurement " $T_{\text {high" }}$ " (boiling water) and one in the low end or measurement " $T_{\text {low" }}$ (bath of ice). The corrected value is obtained by the Equation 1.

$$
T_{\text {corrected }}=\frac{\left(T-T_{\text {low }}\right) \cdot\left(T_{\text {Re fHigh }}-T_{\text {Re fLow }}\right)}{T_{\text {high }}-T_{\text {low }}}
$$

\section{Results}

The results of the time response experiment for all sensors are showed in Fig. 3. These recorded temperatures comprising the transfer between the ice bath and the boiling water were used for representing the time response curves and calculating the time constant for each sensor. As expected, encapsulate RTDs (RTD3) have a much higher time response than the rest of sensors. The thin film RTDs and the three types of TC have a low and similar time response; though TC3 has a little more thermal inertia because of its higher mass.

Relating to the time response, thermocouples and RTDs of lower inertia showed a very similar response. The time constant $\tau$ for the thin film RTD sensors is between 0.2 and 0.3 seconds and between 0.3 and 0.4 second for the slim thermocouples. Their response can almost be compared with a zero order system and is so fast for both types of sensors that the recorded data have not enough resolution for the precise determination of the time constant. This problem is due to the sampling rate of the data acquisition modules (10 samples per second) which is not sufficient to determine precisely such a response. The sampling rate of the ADAM modules needs to be taken carefully in consideration: the more sensors connected to the module, the less sample frequency for each as the sampling rate should be divided between them.

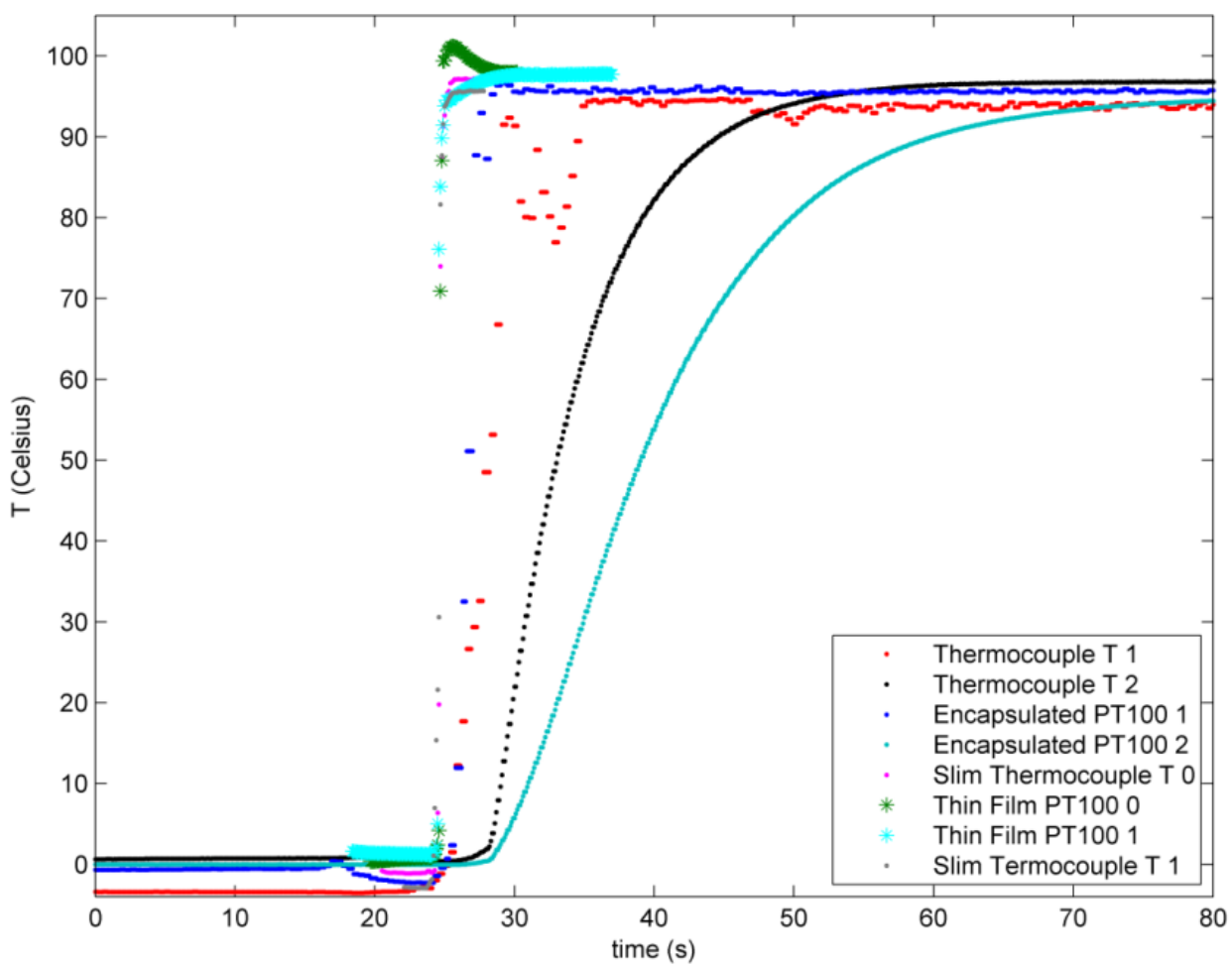

Fig. 3. Time response curves for RTD and TC sensors connected to ADAM modules 
Experiments conducted for the observation of hysteresis phenomena and inhomogeneity on thermocouples did not shown relevant differences and so no error would be expected due to any of these causes.

Calibration tests were conducted during 40s after temperature stabilization in boiling water (Fig. 4) and in icewater (Fig. 5) baths. The output error of the sensing system shows no differences in absolute value between the waterice and the boiling water baths.

The variation coefficients are lower in water-ice bath than in boiling water. The higher variability observed at boiling water temperature can be due to the presence of water-vapor bubbles and turbulent flux in the boiling bath that disturbs the measurements. The random of the TCs and RTDs tested is similar (between $0.14-0.24^{\circ} \mathrm{C}$ ) except in the case of the RTD3 (Table 3). This encapsulated sensor with higher mass and inertia is less affected by rapid changes of temperature. The systematic error of the RTD sensors at boiling point is very homogeneous and always below (around $0.30^{\circ} \mathrm{C}$ ) the actual value of boiling temperature. In the case of TC, the systematic errors in the boiling and ice baths are more variable between the three different TC tested.

Table 3. Calibration of temperature sensors at boiling and freezing points of distilled water

\begin{tabular}{|c|c|c|c|c|}
\hline Sensor & $\begin{array}{c}\text { Temperature } \\
\text { (Celsius) }\end{array}$ & Error & $\begin{array}{c}\text { Temperature } \\
\text { (Celsius) }\end{array}$ & Error \\
\hline & \multicolumn{2}{|c|}{ boiling water bath $\left(97.81^{\circ} \mathrm{C}\right)$} & \multicolumn{2}{|c|}{ ice-water bath $\left(0^{\circ} \mathrm{C}\right)$} \\
\hline TC1 & $98.16 \pm 0.24$ & 0.35 & $-0.19 \pm 0.03$ & -0.19 \\
\hline TC2 & $97.84 \pm 0.22$ & 0.03 & $-0.39 \pm 0.04$ & -0.39 \\
\hline TC3 & $97.70 \pm 0.14$ & -0.11 & $-0.19 \pm 0.04$ & -0.19 \\
\hline RTD1 & $97.50 \pm 0.23$ & -0.31 & $-0.24 \pm 0.10$ & -0.24 \\
\hline RTD2 & $97.51 \pm 0.14$ & -0.3 & $-0.16 \pm 0.04$ & -0.16 \\
\hline RTD3 & $97.52 \pm 0.05$ & -0.29 & $-0.221 \pm 0.009$ & -0.221 \\
\hline
\end{tabular}

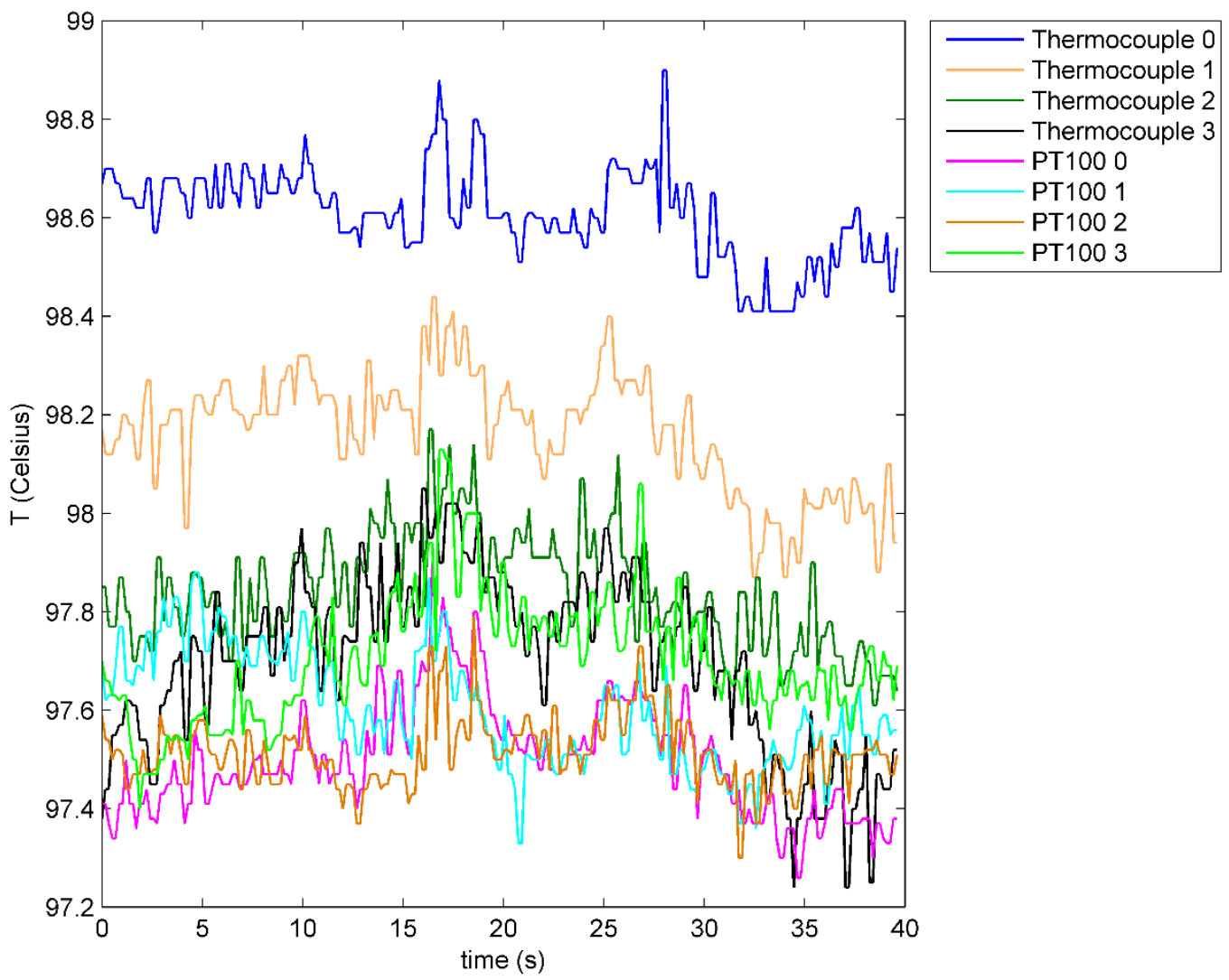

Fig. 4. Calibration test at boiling water bath 


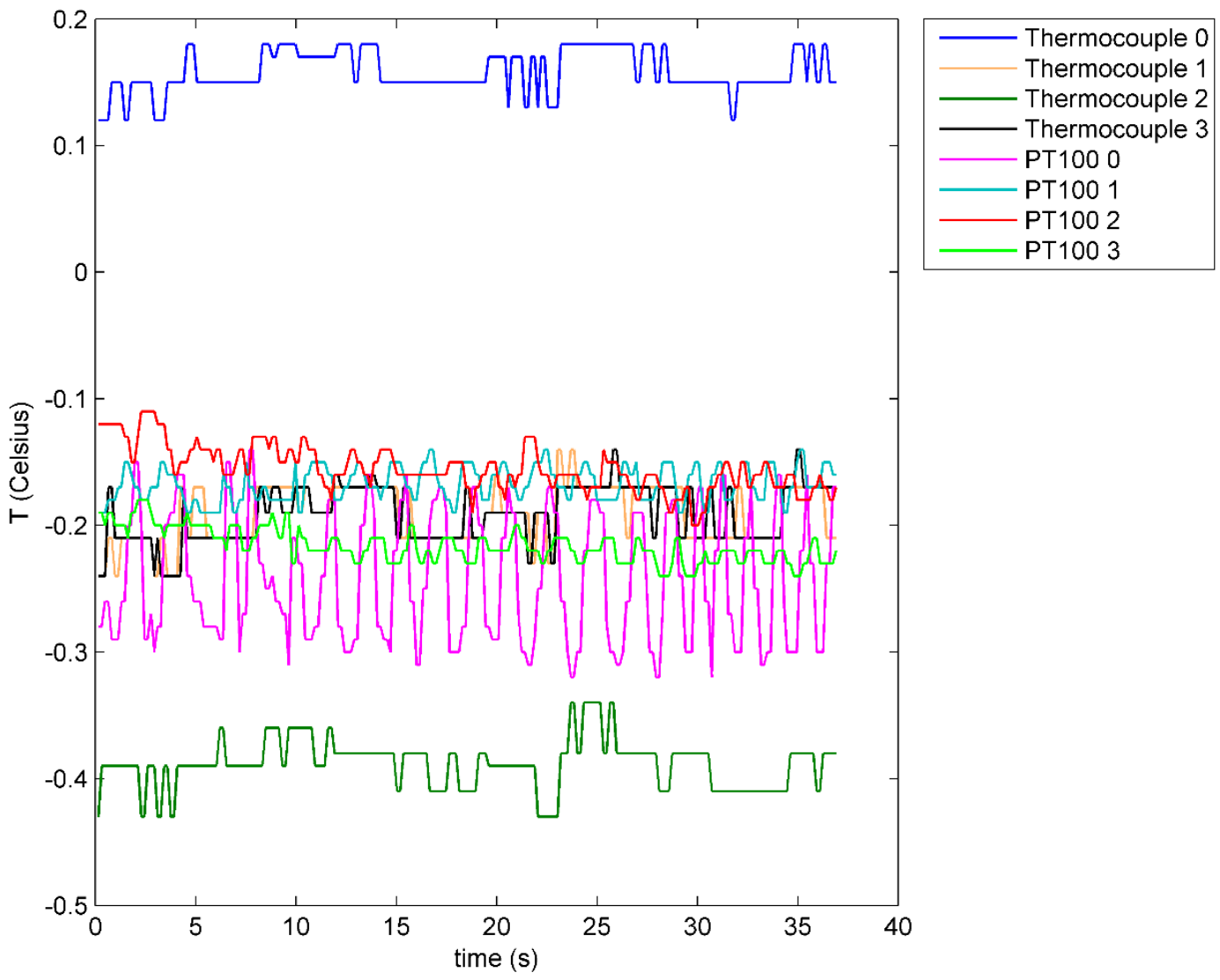

Fig. 5. Calibration test at ice-water bath

Once performed the calibration correction by means of Equation 1, the total error will be assumed to be the random error and thus will not exceed $\pm 0.3^{\circ} \mathrm{C}$ for every sensor.

\section{Conclusion}

Emissivity estimation procedures for agricultural samples should be reviewed in order to determine specific values adapted to current applications. The precise determination of kinetic temperatures of samples and reference materials will improve the results obtained on these procedures.

Evaluation of contact temperature sensors and its suitability for the aforementioned measurements can contribute to the improvement of the procedures and thus on the emissivity values obtained. Both accuracy and precision as well as time response are critical parameters when dealing with contact temperature sensors for emissivity estimations as every sensor error will contribute to erroneous estimations.

Calibration procedure could lead to more precise temperature measurements and even more to the possibility of accounting for limiting error and its contribution to the emissivity estimation error.

When dealing with low mass specimens, temperature can change rapidly under experimental conditions and thus, low mass sensors of very little thermal inertia, in combination with high frequency data recording will avoid significant errors. 


\section{REFERENCES}

[1] Rubio E, Caselles V, Badenas C. Emissivity Measurements of Several Soils and Vegetation Types in the 8-12 $\mu \mathrm{m}$ Wave Band: Analysis of Two Field Methods. REMOTE SENS. ENVIRON. 1997;59:490-521

[2] Van Alstyne K.L., Olson T.K. Estimating variation in surface emissivities of intertidal macroalgae using an infrared thermometer and the effects on temperature measurements. Mar. Biol. 2014; 161: 1409-1418. doi: 10.1007/s00227-014-2429-3.

[3] Minkina W., Dudzik S., Grys S. 2010. Errors of thermographic measurements - exercises. In: Proceedings of QIRT; 2010; Québec, Canada.

[4] Minkina W., Dudzik S. 2009. Infrared Thermography. Errors and Uncertainties. John Wiley \& Sons, Ltd. pp 1192

[5] Alvino A., Marino S. Review: Remote Sensing for Irrigation of Horticultural Crops. Horticulturae 2017, 3, 40; doi:10.3390/horticulturae3020040

[6] Peters, R.T., Evett, S.R. Spatial and temporal analysis of crop stress using multiple canopy temperature maps created with an array of center-pivot-mounted infrared thermometers. Trans. ASABE 2007, 50, 919-927.

[7] Lamm, F.R.; Aiken, R.M. Comparison of Temperature-Time Threshold-and ET-based irrigation scheduling for corn production. In Proceedings of the 2008 ASABE Annual International Meeting, Providence, RI, USA, 29 June-2 July 2008.

[8] O'Shaughnessy, S.A.; Evett, S.R.; Colaizzi, P.D.; Howell, T.A. Soil water measurement and thermal indices for center pivot irrigation scheduling. In Proceedings of the International Irrigation Association Conference, Anaheim, CA, USA, 2-4 November 2008. 